\title{
MODULACIONES NARRATIVAS EXPERIMENTALES EN LOS CUENTOS DE LOS MUERTOS, DE ÁLVARO BISAMA
}

\author{
Felipe Adrián Ríos Baeza \\ Universidad Anáhuac, Campus Querétaro (México) \\ feliperios.ffyl@gmail.com
}

\begin{abstract}
Resumen: Este ensayo pretende, primero, establecer algunos puntos teóricos primordiales para debatir sobre el "anticuento", considerando, bajo la perspectiva lingüística y narratológica, su complicado establecimiento como género alternativo en su propia constitución y naturaleza. Más que notar textualidades reunidas bajo el nombre de "anticuento", lo que este trabajo propone analizar, en su primera parte, son las diversas transgresiones experimentales que la narrativa ha tenido, sin que aquellas constituyan en realidad una ruptura de la estructura profunda del género cuento. A continuación, en la segunda parte se examinarán cómo los relatos del libro Los muertos (2014, reeditado en 2019 por DeBolsillo), del escritor chileno Álvaro Bisama, se aprovechan de dichas transgresiones, desafiando las expectativas del cuento tradicional a través de dispositivos literarios que pueden analizarse como patrones reiterados en su obra (la presencia de la cultura masiva o posmoderna como fachada; el uso de narradores falibles; la metaliteratura como ejercicio autorreflexivo, entre otros). Esto con la finalidad de determinar hasta qué grado esta experimentación estira los límites estructurales y genéricos del llamado cuento tradicional, produciéndose, en realidad, una focalización no tanto en las acciones, sino en los grados de trasformación interna de sus personajes y en la intención de dialogar con el contexto histórico y cultural.
\end{abstract}

Palabras clave: anticuento, Álvaro Bisama, literatura chilena, autorreflexión, géneros literarios.

\section{EXPERIMENTAL NARRATIVE MODULATIONS IN THE SHORT STORIES OF ÁLVARO BISAMA'S LOS MUERTOS}

\begin{abstract}
This paper pretends, first of all, to establish some main theoretical points to debate about the anti-story, considering under the linguistic and narratological perspective its complicated establishment as an alternative genre on its own constitution and nature. More than textualities gathered under the name of anti-story, this work proposes to analize on its first part the different experimental transgressions that the narrative has had, without those constituting a rupture of the profound structure of the "short story" genre. Then, in the second part it will examine how the short stories of the book Los muertos (2014, re-edited in 2019 by DeBolsillo) of the Chilean writer Álvaro Bisama, take advantage of those transgressions, defying the expectations of the traditional short story through literary devices that can be analized as reiterating patterns in his work (the presence of the low or postmodern culture as a facade; the use
\end{abstract}


of falible narrators; the meta-literature as an auto-reflexive exercise, among others). This with the purpose to determine how this experiment pushes the structural and generic limits of the traditional tale, resulting in a focus not only on the actions but also on the internal transformation of its characters and the intention to dialogue within the historical and cultural context.

Keywords: anti-story, Álvaro Bisama, Chilean literature, auto-reflection, literary genres.

DOI: https://doi.org/10.24029/lejana.2019.12.392

Recibido: el 11 de abril de 2019

Aceptado: el 25 de agosto de 2019

Publicado: el 30 de octubre de 2019 


\section{Prolegómenos teóricos: ¿anticuento o cuento experimental?}

Entraña a los procedimientos narrativos del siglo XX el mestizaje o, derechamente, la desintegración de formas y de géneros literarios. La obra de Alain Robbe-Grillet, James Joyce, André Gide y Phillipe Sollers, por ejemplo, o en nuestra lengua la propuesta de Julio Cortázar, Josefina Vicens, Salvador Elizondo y Enrique Vila-Matas, han obligado a la crítica a replantear sus modos de análisis y valoración para interpretar, con mayor acierto, de qué manera un ensayo puede ser fecundado con elementos autobiográficos o una novela es capaz de enunciarse a través del lirismo y de discursos literarios más privados, como la epístola o el diario de vida. No obstante, frente a la novela, el cuento — sin duda el género literario con mayor plasticidad— 1 parece resistir los embates y las excesivas variaciones, al menos en su morfología. Tiene razón Enrique Anderson Imbert cuando en su libro Teoría y técnica del cuento (1979) señala que:

En el deseo de experimentar es fácil que un narrador llegue a la antinovela; es difícil que llegue al anticuento. ¿Por qué? Porque el cuento, por ser breve, capta una acción única y le da forma en una trama rigurosamente construida; y esta trama es tan recia que se resiste mejor que la novela la desintegración formal. Los cuentos renuevan también sus técnicas; sólo que los experimentos técnicos, en el cuento, no consiguen deshacerlo. (2007: 48)

Desde los inicios de la reflexión teórico-literaria se viene pensando que todo relato tiene, en su núcleo primordial, la estructura del drama (una división de actos que, en términos archiconocidos, se transmuta hacia la narrativa con los nombres planteamiento-nudodesenlace). La reconocida definición aristotélica de la poesía (entendida en tanto "literatura") como mímesis de acciones (1999: 266), y la posterior focalización analítica en esas precisas acciones, ${ }^{2}$ conlleva un fundamento que no variará demasiado cuando los formalistas, los estructuralistas y los narratólogos revisiten este concepto. Para que exista un relato deben concatenarse acciones bajo el principio de causalidad, es decir, de manera lógica y progresiva: una acción necesita desencadenar, mantener o clausurar una secuencia de eventos realizada por uno o más personajes. ${ }^{3}$ La característica narratológica e incluso lingüística ${ }^{4}$ de todo texto en prosa

\footnotetext{
${ }^{1}$ Pensemos en Mijaíl M. Bajtín, que definió la plasticidad como "la diversidad social, organizada artísticamente, del lenguaje; y a veces, de lenguas y voces individuales" (1975: 81).

${ }^{2}$ Cfr. Aristóteles, Poética: “[L]os personajes son tales o cuales según el carácter; pero, según las acciones, felices o lo contrario. Así, pues, no actúan para imitar los caracteres, sino que revisten los caracteres a causa de las acciones. De suerte que los hechos y la fábula son el fin de la tragedia, y el fin es lo principal en todo" (1999: 148).

3 Así, Mieke Bal, por ejemplo, marca que: "Los acontecimientos han sido definidos [...] como la transición de un estado a otro que causan o experimentan actores. La palabra «transición» acentúa el hecho de que un acontecimiento sea un proceso, una alteración" (2009: 21); y Helena Berinstain, en tono más didáctico, afirma: "El cuento se caracteriza porque en él, mediante el desarrollo de una sucesión de acciones interrelacionadas, lógica y temporalmente, la situación en que inicialmente aparecen los protagonistas es objeto de una transformación" (1995: 129).

${ }^{4}$ Cfr. Roman Jakobson, "Dos aspectos del lenguaje y dos tipos de trastornos afásicos": "El principio de la semejanza rige la poesía; el paralelismo métrico de los versos o la equivalencia fónica de las palabras que riman suscitan la cuestión de la semejanza y el contraste semánticos; existen, por ejemplo, rimas gramaticales y antigramaticales, pero nunca rimas agramaticales. La prosa, en cambio, se desarrolla ante todo por contigüidad. Por lo tanto, la metáfora, en poesía, y la metonimia, en prosa, constituyen las líneas de menor resistencia, y a causa de ello el estudio de los tropos poéticos se dedica fundamentalmente a la metáfora. La bipolaridad que realmente existe se ha reemplazado en estos estudios por un esquema unipolar amputado que coincide de manera sorprendente con una de las formas de la afasia, o sea, con el trastorno de la contigüidad" (1980: 145).
} 
sería, entonces, la dominancia del eje sintagmático del lenguaje: avance horizontal y relación de contigüidad de sus unidades de sentido. En un cuento hay eventos que llevan a otros, y a través de ellos los personajes cambian, ya sea porque ejecutan o se someten a dichas acciones.

Bajo estos criterios, ¿a qué hemos, pues, ido llamando "anticuento"? El ensayista Juan Carlos Palazuelos menciona, sin establecer tampoco una taxonomía tan clara en su estudio, que el fundamento inherente de todo "anticuento" es que:

[N]o existe el desarrollo de un proceso accional. Aquí las secuencias no funcionan [...] como unidades integrativas, es decir, no constituyen una malla de procesos y microprocesos válida por sí misma, sino que, como totalidades, indexan estados de ánimo, formas de vida, características de los personajes, etc. (2003: 105, cursiva en el original)

Quizás, como explicaba Anderson Imbert, en ese intento de "deshacer" el cuento en tanto forma narrativa, lo que plantearon ciertos narradores de vanguardia en el siglo XX (Macedonio Fernández, Pablo Palacio, Martín Adán, Gilberto Owen, Arqueles Vela, etc.) fueron en realidad experimentaciones, en términos de enunciación y temática, pero su estructura profunda permaneció más o menos intacta.

Por lo tanto, después de este periplo teórico cabría preguntarse: ¿existe realmente el "anticuento"?, ¿es "anticuento" todo texto que se anuncia como cuento, pero que atenta contra el proceso accional?, ¿y en qué grado, además: total o parcialmente? ${ }^{5}$ Por decirlo pronto: sacrificar, pues, la causalidad de acciones en realidad no lleva a que emerja algo llamado "anticuento", sino a la presencia de otro tipo de texto distinto del narrativo: texto descriptivo o reflexivo; texto dialógico; o bien textos donde no hay más que otra vuelta de tuerca a la propuesta chejoviana donde el desenlace queda suspendido.

En resumen, lo que ha acontecido es un ajuste a la teoría de la narrativa para poder absorber e interpretar la experimentación que dentro de los límites del género cuento fenómenos como la patafísica jarryana, la nouveau roman, el nuevo cuento hispanoamericano o el OuLiPo han ido generando, en tanto cuestionamiento al esquema triádico tradicional de planteamientos, nudos y desenlaces. Y el ajuste parece ser el siguiente: el "cuento experimental" (que no "anticuento", al no desbaratar su estructura profunda) rebaja el protagonismo de las "funciones cardinales" que mueven al relato (para usar la terminología de Roland Barthes) y le da realce a aquellos elementos que permanecen en un nivel secundario, al considerarse meras "catálisis", "indicios" o "informantes" (dibujo psicológico de los personajes, profusión lírica,

\footnotetext{
${ }^{5}$ Palazuelos intenta ser enfático en esto: “[L]a experimentación literario-narrativa, incluso la más extrema (en anticuento y la antinovela), pertenece a la tradición (cuentística o novelística) y, por lo tanto, está integrada al sistema. La experimentación deja de integrar el sistema precisamente cuando lo transforma, es decir, cuando se convierte en tradición creadora de un modelo nuevo (dando origen, por lo tanto, a una nueva experimentación, integrada, esta vez, al nuevo sistema). Desde este punto de vista, el anticuento y la antinovela pueden considerarse modelos secundarios paralelos de menor prestigio" (2003: 143).

${ }^{6}$ En "Introducción al análisis estructural de los relatos", Barthes reconoce que todos los elementos dispuestos en un relato son "funcionales", pero no todos tienen la misma importancia. Existen funciones cardinales que operan como verdaderos nudos del relato y que constituyen aquello que hace avanzar la narración. Esta "armazón de acciones del relato" puede estar complementada con funciones catálisis (eventos secundarios que complementan los espacios narrativos entre una función cardinal y otra); indicios (elementos difusos, implícitos, pero necesarios para dar identidad, atmósfera y, sobre todo, para sugerir información que luego se hará relevante) e informantes (datos
} 
argumentación ensayística, diálogos, descripción dramática, etcétera ${ }^{7}$. Es lo que también László Scholz reconoce en su libro Los avatares de la flecha. Cuestionamiento del principio de linealidad en el cuento moderno hispanoamericano:

El cuento moderno, tendente a renovar del género, trata sobre todo de romper el funcionamiento de estos principios y busca recursos que los debiliten o sustituyan. Se trata de un metódico ataque contra la linealidad también en la parte media del cuento, cuestionando el mismo concepto de tiempo, espacio y las relaciones causales de la narrativa breve tradicional, y cambiando también la sencilla relación antitética entre el inicio y el final. Las formas de este cuestionamiento suelen ser enfáticamente negativas: se basan en vacíos y elipsis, o [...] en ausencias. (2001: 48)

Asumido aquello, y actualizando el corpus propuesta por Scholz (que va del cuento moderno al relato de los años 70 y 80 ), es posible identificar en la literatura hispanoamericana del siglo XXI dos fenómenos claros: por un lado, cuentistas que retornan a la elaboración de un cuento bastante tradicional (al modo de Cortázar o Bioy Casares) para provocar los efectos deseados, debido a que varios se adscriben al fantástico y necesitan eso que Julio Cortázar llamaba "knock out", (Samanta Schweblin, con Pájaros en la boca y otros cuentos [2009]; Luciano Lamberti, con El loro que podía adivinar el futuro [2012]; y Mariana Enríquez, con Las cosas que perdimos en el fuego [2016], entre otros); y por otro lado, aquellos escritores que buscan todavía vulnerar algo de su morfología y modular su causalidad, ya no para derrumbar el edificio del género, pero sí para abrirle efectivas fisuras con el propósito de que el lector pueda recrearse de otro modo en la experiencia literaria. ${ }^{9}$ A este último grupo pertenecerían, por ejemplo, Fabián Casas, con Los lemmings y otros, de 2005 (volumen cuyos cuentos pueden ser leídos de manera independiente o bien como capítulos consecutivos de una novela fuertemente autoficcional); José Sánchez Carbó, con En realidad no es una historia de amor, también de 2005 (en la línea de Casas, un libro donde hay una conciencia clarísima de generar un hilo conductor entre cada una de las unidades cuentísticas, al punto de que el propio Sánchez Carbó desarrolló,

precisos, inmediatamente significantes, que proporcionan un conocimiento ya elaborado): "Todo, en un relato, ¿es funcional? Todo, hasta el menor detalle, ¿tiene un sentido? ¿Puede el relato ser íntegramente dividido en unidades funcionales? Como veremos inmediatamente, hay sin duda muchos tipos de funciones, pues hay muchos tipos de correlaciones, lo que no significa que un relato deje jamás de estar compuesto de funciones: todo, en diverso grado, significa algo en é1 [...]. Para retomar la clase de las Funciones, digamos que sus unidades no tienen todas la misma «importancia»; algunas constituyen verdaderos «nudos» del relato (o de un fragmento del relato); otras no hacen más que «llenar» el espacio narrativo que separa las funciones «nudo»" (Barthes, 2003: 20).

${ }^{7}$ Siguiendo, aunque con cierto cuidado, la clasificación sugerida por Philip Stevick en Anti-Story: An Anthology of Experimental Fiction (1971), bajo este criterio se encontraría el cuento metaficcional, el cuento fantástico, el cuento como crónica, el cuento como deriva, el cuento como viaje interior, el cuento fenoménico, el cuento de lo absurdo y el cuento ultracorto. Como se ve, todos aquellos intentos persiguen alterar temáticas y alguna de las partes del armazón de funciones cardinales, pero sin conseguir hacer emerger un género inédito en sí. Vid. Philip Stevick, "Introduction" (en Anti-Story: An Anthology of Experimental Fiction, 1971: ix-xiv).

${ }^{8}$ Recordando: "En ese combate que se entabla entre un texto apasionante y su lector, la novela gana siempre por puntos, mientras que el cuento debe ganar por knock-out. Es cierto, en la medida en que la novela acumula progresivamente sus efectos en el lector, mientras que un buen cuento es incisivo, mordiente, sin cuartel desde las primeras frases" (Cortázar, 1994: 372).

9 Al respecto, Pablo Brescia ha establecido hace poco un reparto referencial parecido para la literatura hispanoamericana del siglo XX que podría aplicarse, en parte, para lo que hemos ido viendo en el siglo XXI: "[En] la teoría del cuento, pondera la lucha entre dos impulsos en apariencia contradictorios en el género: su vocación experimental y su afán de estructura cerrada" (2014: 66). 
luego, una teoría sobre ello) ${ }^{10}$; Claudia Apablaza, con Diario de las especies, de 2008 (libro construido como si fuese un blog, donde cada entrada se alimenta, reformula o retracta debido a los comentarios de los lectores); y Álvaro Bisama, con Los muertos, de 2014, el volumen que nos ocupará en la siguiente parte de este ensayo.

\section{Narradores falibles: salvando el lugar de enunciación}

Los relatos reunidos en el volumen Los muertos, de Álvaro Bisama, escritor chileno de obra compleja y profusa, ${ }^{11}$ desafían las expectativas del cuento tradicional a través de dispositivos literarios que pueden analizarse como patrones reiterados en su obra (la presencia de la cultura masiva o posmoderna como fachada; la aparición de narradores falibles; la metaliteratura como ejercicio autorreflexivo, entre otros). Es primordial determinar hasta qué grado esta experimentación estira los límites estructurales y genéricos del llamado cuento, produciéndose una focalización no tanto en las funciones cardinales, sino en los grados de trasformación interna de sus personajes y en la intención de dialogar con el contexto histórico y cultural, allí donde, quizás, esté el "planteamiento" o el "desenlace" que varios de sus relatos elípticamente van a omitir.

Una de las primeras ensayistas en analizar con detenimiento el volumen fue Alejandra Bottinelli: "Uno lee Los muertos como si se tratase de un comentario de un estado del espíritu, del ánima postdictatorial, donde los muertos, los que han estado muertos de la palabra, cobran vida. Son vicisitudes, anécdotas, de una densidad de tiempo, espesura y proyección sobre todo en el ambiente: marcas en el cuerpo de la época" (2016: 17). Coincidimos con ella en parte. En este libro de relatos aparecen los temas "bisamianos" por antonomasia: cajeras de supermercado que

\footnotetext{
${ }^{10}$ Cfr. José Sánchez Carbó, La unidad y la diversidad. Teoría e historia de las colecciones de relatos integrados: "La colección de relatos integrados resulta así una modelización literaria caracterizada porque un autor reúne y organiza en un libro una serie de textos autosuficientes que, relacionados hipotáctica o paratácticamente, configuran, con la colaboración del lector, un todo coherente y permiten un orden de lectura sucesivo o salteado" (2012: 46).

${ }^{11}$ Aunque en España y México Álvaro Bisama es un escritor que recién está comenzando a tener presencia significativa, en Sudamérica es un nombre que lleva tiempo posicionando su propuesta. A principios de siglo, Bisama comenzó a hacerse conocido por ser un colaborador vigoroso en suplementos culturales de periódicos como El Mercurio, donde, así como hablaba de José Donoso y Nicanor Parra, podía reseñar a Miguel Serrano, Jodorowsky, Stephen King o el cómic El Eternauta, de los argentinos Héctor Germán Oesterheld y Francisco Solano López. Con una clara intención de combinar los registros de la high y la low culture, donde cabía el canon literario trufado con películas de cine B y discos de heavy metal, en 2006 publicó Caja negra, libro en el que un músico japonés, Takeshi Osu, y cineastas como Samuel Levinas y los hermanos Mori sirven como elementos de enlace entre los distintos eventos paranormales, cantantes glam, dibujantes de cómic y referentes apócrifos del cine de terror chileno. Este libro fue pionero de un breve, pero potente movimiento que fue bautizado como freak power (en el que entraron, también, Jorge Baradit y Francisco Ortega), y que ayudó a sacudir a una novela chilena que se había anquilosado en la memoria dictatorial, el realismo y la apropiación de ciertos lugares de enunciación que se agotaron pronto, como el de la infancia bajo el régimen militar. Bisama sacó a relucir, con una prosa ágil, fragmentaria y directa, elementos de la ciencia ficción, el terror y el relato fantástico, sin inscribirse de manera militante en ninguno de esos géneros, pero permitiendo que Santiago y sus provincias cercanas, como Villa Alemana, fueran mirados desde la cultura popular más cautivante. A Caja negra le siguieron las novelas Música marciana (2008), Estrellas muertas (2010), Ruido (2012), Taxidermia (2014), El brujo (2016) y Laguna (2018); los libros de crítica y ensayo Cien libros chilenos (2008), Televisión (2015) y Deslizamientos (2016); y el volumen de cuentos Los muertos (2014), recientemente reeditado por DeBolsillo, de Random House Mondadori, en 2019.
} 
se cortan los muslos con navajas y escuchan death metal ("Remix"); escritores anónimos de sagas fantásticas ("La dieta del orco"); ladrones de coches que parecen ver fantasmas ("Arena negra"); fanáticos del skateboard ("Noize"); mujeres que están esperando sin dormir a que les llegue la muerte ("Ciento sesenta y dos mil ochocientos segundos") y fetichistas de objetos relacionados con Adolf Hitler ("Muchacha nazi"), entre otros seres extravagantes. Todos los relatos, eso sí, parecen tener un común denominador, y este es la focalización obsesiva en un personaje que camina al borde de los abismos (sociales, psicológicos o emocionales), pero que rara vez cuenta su propia historia. Es decir, lo que tenemos es un vivo conjurando a los muertos que, al cancelar la posibilidad de la autodiégesis, produce como resultado una distancia con historias que a la larga resultarán tapices agujereados; tapices entre cuyos intersticios se escurrirá la posibilidad de averiguar todos los detalles del devenir de los protagonistas. El trabajo de construcción de la narración deviene, siempre, en términos homodiegéticos (narradores testigos, pero externos a la historia principal). Esta es la razón principal de por qué estos relatos se quedan suspendidos, no terminan o resultan solamente la exhibición de los "nudos" de la estructura triádica del cuento regular, dejando fuera "planteamientos" y "desenlaces" y trabajando lo que Scholz mencionaba como «formas de cuestionamiento enfáticamente negativas» al relato al uso.

En el homónimo relato "Los muertos", por ejemplo, se narra la historia de un viejo periodista de izquierda que escribía notas de divulgación científica y que tuvo que exiliarse tras el golpe de estado de 1973. Quien la cuenta, un profesor universitario, dice en los prolegómenos: "Yo aparezco un poco, quizás como una excusa para contarla, para cerrarla" (2014: 19), teniendo clara conciencia de su labor. No obstante, es poco lo que vívidamente ha interactuado con el periodista, y los detalles de su destino los conoce a través de su propio padre y de otra profesora, que había sido pareja del personaje. El narrador reseña apenas los libros que el periodista publicó. Comenta, luego, el desdén que siente el periodista por esos libros. Al final, habla de una instalación realizada en uno de los patios de la universidad en la que trabaja, ${ }^{12}$ que rememora los libros quemados por la dictadura. Se sorprende al hallar uno del viejo periodista. El relato concluye aportando ciertas claves de lectura no solo para el mismo, sino para la totalidad del volumen:

Esta tarde hice clases y luego me vine a la casa y escribí esto de un viaje. No sé si le hace justicia. No me importa.

(No creo que tenga ninguna relevancia pero la clase fue sobre Los muertos de Joyce).

\footnotetext{
12 Asunto que, aunque de carácter extradiegético, de todos modos es importante consignar porque, como veremos luego al analizar el cuento "Pozo", Bisama emplea el recurso de los puentes entre el texto y ciertos contextos verificables para empezar, continuar o acabar un relato. En este caso, en efecto, entre el 26 de agosto y el 30 de noviembre del año 2013 tuvo lugar una instalación en el patio de la Biblioteca Nicanor Parra, de la Universidad Diego Portales sobre libros quemados y prohibidos en dictadura, institución donde Bisama efectivamente trabaja coordinando la licenciatura en Literatura Creativa. La página de la Universidad lo consignó así: "Muchos libros, por temor o represión, fueron quemados, escondidos o enterrados en miles de hogares e instituciones chilenas, configurando un espectro de autores, títulos y temáticas silenciadas, imposible ya de precisar y cuantificar. Se quemaron o destruyeron millones de libros, desde fábulas a literatura universal, pasando por escritores latinoamericanos o sencillamente publicaciones educativas, culturales, filosóficas o políticas. Es nuestro deber hacer este ejercicio de memoria y recuperación a partir de una exposición que se abre como campo de investigación de nuestra historia" (UDP, 2013: párr. 2).
} 
Me di cuenta de que lo único que tenía era el boceto de una sombra, el esqueleto de una novela que no crecerá jamás, un cuerpo hecho de humo y ectoplasma.

Esto. (2014: 27)

Hay en esta cita varios asuntos clave. Primero, el reconocimiento de que la empresa que se había propuesto, cerrar la historia, no ocurre satisfactoriamente, trasgrediendo con ello las características del esperado desenlace de toda estructura dramática. Segundo, una voluntad de tomar en sus manos retazos de la historia de un muerto o desaparecido no necesariamente por los aparatos represivos de Pinochet, sino por la misma memoria colectiva, pero al final lo que exhibe es una suerte de displicencia ("no sé si le hace justicia. No me importa"). Tercero, como en un juego de matrioshkas, se evidencia la incorporación dentro de este dispositivo de los narradores poco fiables de otro dispositivo experimental: la reflexión de ese mismo narrador acerca de lo que está contando. Al final del recorrido, no hay más que el "boceto de una sombra", el "esqueleto de una novela que no crecerá jamás, un cuerpo hecho de humo y ectoplasma”, características primordiales que no solo sirven para describir este, sino el resto de los diez cuentos que completan el libro. Y cuarto (tal vez uno de los asuntos más decisivos): la indiferencia al aportar un dato que es en suma relevador: este profesor universitario, inserto como narrador en un cuento llamado "Los muertos" dentro de un volumen llamado Los muertos, ha dictado una clase sobre el relato homónimo de James Joyce y, por lo tanto, es consciente de su trama y de sus mecanismos de funcionamiento. Recordemos que en el relato de Joyce, ${ }^{13}$ debajo de la celebración de fin de año en un superficial ambiente patriótico dublinés, en donde se habla de "aquellos que ya no están”, el protagonista Gabriel Conroy ve cómo va emergiendo la demoledora revelación final de su esposa Greta: aquella donde confiesa que su corazón sigue atado al de Michael Furey, joven que se suicidó por amor cuando ambos eran muy jóvenes.

Aquí hay dos cosas interesantes para poder, incluso, hacer un análisis comparativo e intertextual entre "Los muertos" de Joyce y "Los muertos" de Bisama. Ante todo, ¿cómo procesar en el presente a los muertos, tanto personales (el pretendiente de Greta) como colectivos (los muertos y desaparecidos en dictadura)? Porque esas ausencias se intensifican, se idealizan, ocupan la totalidad de muchas conciencias y son bien motor, o bien parálisis de aquellos que quedaron vivos; y por otro lado, un asunto más técnico del cuento de Joyce, del que Bisama sabe sacar mucho provecho: en la revelación final que hace Greta y escucha Gabriel, el narrador joyceano afirma: “Quizás no le había contado toda la historia” (Joyce, 1994: 345).

No contar toda la historia. Derivar la atención hacia otros sitios. Omitir, en tanto elipsis, partes de la historia en la trama. Se trata, pues, de un dispositivo que Bisama también emplea para vulnerar el canon del género y abrir la reflexión hacia otras zonas de la narración, ${ }^{14}$ y por

\footnotetext{
${ }^{13}$ Que no por nada es ocupado por Ricardo Piglia, en "Tesis sobre el cuento", como ejemplo primordial para plantear una variante de su teoría de que un cuento siempre cuenta dos historias: "La versión moderna del cuento que viene de Chéjov, Katherine Mansfield, Sherwood Anderson, y del Joyce de Dublineses, abandona el final sorpresivo y la estructura cerrada; trabaja la tensión entre las dos historias sin resolverla nunca. La historia secreta se cuenta de un modo cada vez más elusivo. El cuento clásico a la Poe contaba una historia anunciando que había otra; el cuento moderno cuenta dos historias como si fueran una sola" (Piglia, 2000: 108).

${ }^{14}$ Como ya hemos afirmado en otras ocasiones, es posible que Bisama aprenda estas modulaciones narrativas no solo de autores lejanos, como Joyce, sino de uno de sus referentes más próximos: Roberto Bolaño. Recordemos, por
} 
eso, aunque el narrador quiera restarle relevancia, el lector (o el narratario) no pasa por alto la mención a "Los muertos", de Joyce.

En otros momentos del volumen, pueden leerse las siguientes frases por parte de los narradores cuyo perfil elusivo y encubridor es más que evidente: "Esta es una historia que completé accidentalmente y funciona como una fábula [...]. He completado los pedazos al azar, sin buscarlo" (2014: 19); "yo no supe detalles de su relación” (2014: 20); "me dijo el nombre de la enfermedad, pero no lo retuve. No importa" (2014: 32); "Soñé una y otra vez [...]. Todo para hablar con alguien. Todo para contarme una historia" (2014: 108-109); "Yo no sé mucho. Me sé la parte de acá" (2014: 147). ¿Qué nos dicen estas frases? Una conclusión, primero, denotativa: que el narrador carece de las piezas para armar completa cualquier historia. Aunque emerge luego, y sin mucho esfuerzo, una razón connotativa: el agravante de que, en realidad, llegado a cierto punto no le importa carecer de esa información, por lo que comienza a especular, siendo siempre consciente de estar, quizás, solo describiendo "nudos" o "conflictos", omitiendo "causas" y "consecuencias".

Otro modo de ver al narrador bisamiano: el "sujeto de la enunciación" de la historia, para usar el término de Benveniste, no solo es testimonial de aquellos derroteros con el fin de presentar al protagonista como un ser escurridizo, dinámico y de muy difícil aprehensión (el viejo periodista, en "Los muertos"; Pascal, el hermano fotógrafo del narrador, en "Ho Chi Mihn City"; 15 la muchacha que parece fantasma, en "Arena negra"; el amigo del pueblo que se vuelve punk, en "Death Metal"); sino que también es negligente, tangencial y displicente con ese "sujeto del enunciado". Y es que el narrador de Bisama se fascina por los protagonistas que presenta; se recrea un momento en sus historias; quiere, incluso, emularlos, pero al final defiende, justo, un lugar de enunciación que no quiere ceder porque hay allí una actividad que quiere seguir desarrollando y que siempre tiene que ver con aspectos creativos (escritura, dibujo, pintura, etcétera). Por eso el movimiento habitual de estos cuentos es siempre del referente (la historia de los protagonistas) al proceso de enunciación (la redacción del relato).

De esta manera, sus historias más que acabar se detienen, debido a que los narradores descubren un abismo donde, quizás, la inquietud y el horror son tales que no existan palabras capaces de refractarlos en forma de relato. "[L]o que venía después, era un precipicio" (2014: 115), señala al final el narrador del cuento "Arena negra", ilustrando con esta sentencia la detención del avance del relato por los motivos antes mencionados; y la conciencia de que en lo

ejemplo, cómo la novela Estrella distante cuenta no solo la historia del camaleónico Carlos Wieder, sino, cuando el narrador se ve escaso de materiales para su enunciación, opta por contar la historia del propio proceso de escritura de ese libro; o bien la máxima que aparece en "El secreto del mal": "Este cuento es muy simple aunque hubiera podido ser muy complicado. También: es un cuento inconcluso, porque este tipo de historias no tienen un final" (2007: 23), frase que permite entrever cómo Bolaño fue pensando el género cuento en los últimos tiempos. Estos paralelismos entre Bolaño y Bisama pueden verse profundizados en nuestro capítulo "Criptoanálisis: la ciencia ficción", en Roberto Bolaño: Una narrativa en el margen II. Espacios, tiempos y personajes "marginales" en su obra (2013, 123-136); y en nuestro artículo "Ideología, modelo de mundo y sabotaje en tres cuentos de Álvaro Bisama" (2018).

${ }^{15}$ Este cuento viene de un hipotexto anterior, el capítulo llamado "Ciudad Ho Chi Minh", de la novela de 2008 Música marciana. Podemos pensar que este gesto de auto-apropiación es otro dispositivo que pone en cuestionamiento que el relato arranque siempre con un planteamiento o inicio autónomo. El cuento incluido en Los muertos quizás tenga sus causas, y esto abre otras perspectivas de análisis, en la novela escrita seis años antes. 
profundo de los propios relatos de Bisama hay, de manera autorreflexiva, la clave para que el lector sepa las razones de por qué los cuentos se arman de este modo más experimental. ${ }^{16}$

¿Cuál es, entonces, la posición del narrador en los relatos de Bisama? La del creador contemplativo, consciente de que, en caso de volverse activo, corre el riesgo de disiparse, así como los personajes que recuerda o proyecta. Los narradores, al final, toman una decisión: escriben, declaman o dibujan el caos que han percibido sus sentidos, pero no para vivir algo similar, sino para dejar un registro e intentar comprender, en la medida de lo posible, lo ocurrido.

\section{Hay alguien ahí: el narratario como procedimiento trasgresor}

Así como los narradores parecen tener ciertos factores comunes (no conocen de primera mano la historia referida; están tratando de conjurar lo que han visto al borde del abismo; participan de cierta situación de marginalidad en relación con la norma social y artística) quienes reciben la historia dentro de la narración parecen constituir una misma, sola e indivisible entidad. Aquí nos plegamos a la noción que Gerald Prince articuló bajo el nombre de narratario. ${ }^{17}$ Recordando, esta figura textual puede tener distintas funciones: "[C]onstituye un intermediario entre el narrador y el lector, ayuda a precisar el marco de la narración, sirve para caracterizar al narrador, pone de relieve ciertos temas, hace progresar la intriga, se convierte en portavoz moral de la obra" (Prince, 2001: 161). Pensando que toda narración se construye orientada a un narratario, entonces afirmaríamos, de entrada, que en los once relatos de Bisama el narratario es uno y el mismo, y que a medida que avanza el volumen va ganando una presencia tal que es capaz de

\footnotetext{
${ }^{16}$ En el libro de Philip Stevick, el procedimiento que se denomina "against mimesis" o "fiction about fiction" (1971: xv) puede vincularse aquí con la conciencia de estos narradores que se interrogan acerca de la condición de verdad de las historias que están contando, algo que, por supuesto, delinea teóricamente, en toda su profundidad, el postestructuralismo francés. Usamos el término autorreflexión así como el postestructuralismo lo estudió provechosamente para la literatura. La relación del relato con la verdad de aquello que se está enunciando es un fenómeno que pone en cuestionamiento la representación mimética del mismo, o, para decirlo de otro modo, su posibilidad de capturar los referentes del mundo. Al respecto, puede verse: Michel Foucault: "Lenguaje y literatura"; Roland Barthes: "Sobre la lectura"; y Phillipe Sollers: "Des grandes irrégularités de langage". Como difusión y reseña, también puede ser útil la consulta de: Manuel Asensi Pérez: "Auto-reflexividad y «literatura»", y Felipe A. Ríos Baeza: "Metaliteratura e ideología: Apuntes para una teoría", donde afirmamos que varios relatos hispanoamericanos recientes, como los de Bisama, "trabajan con las trampas de la ficción, entregando inicialmente un texto literario a usanza para luego introducir un giro autorreflexivo, en términos de que el texto "se mira a sí mismo» como una autonomía, poniendo en suspenso su conexión con la realidad de la que supuestamente salió y a la que irá $[\ldots]$. La literatura, acostumbrada a mostrar pero no a mostrarse, tiene en la metaliteratura su posibilidad de revelar los códigos, sus técnicas. La idea es continuar articulando una serie de metodologías en donde se promueva, por un lado, el análisis ideológico; y por otro, el reconocimiento de elementos que tal vez el mismo texto presente, como las auto-parodias, las metalepsis, las autorrepresentaciones y los mise-en-abîme" (2017: 86).

17 Así como existen narradores que emiten la narración, existen dentro del marco narrativo destinatarios, o narratarios, que la reciben. Cada texto tiene uno o más narratarios específicos, que se descubren a partir de diversas señales o marcas textuales del narrador: "Toda narración, sea ésta oral o escrita, relate acontecimientos certificables o míticos, cuente una historia o una simple serie de acciones en el tiempo, presupone no solamente (al menos) un narrador sino también (al menos) un narratario, es decir, alguien a quien el narrador dirige sus palabras [...]. [El narratario] conoce, por ejemplo, la lengua empleada por el narrador; está dotado de una excelente memoria; ignora todo acerca de los personajes que le son presentados [...]. [E]l retrato de un narratario se desprende ante todo del relato que le es hecho [...]. [C]onsideramos que toda narración se compone de una serie de señales destinadas a un narratario" (Prince, 2001: 151, 154).
} 
visibilizar una trasgresión al relato tradicional: que los narradores no importan tanto por su posición de emisores - "Yo aparezco un poco, quizás como excusa para contarla" (Bisama, 2014: 19), decía el narrador del propio cuento "Los muertos"-, sino porque, previamente, han sido narratarios de estas historias y ahora las revelan como un modo de conjurar algo que no acaban de comprender.

Tomemos algunos ejemplos para reforzar este punto (advertimos que, a continuación, todas las cursivas son nuestras). Mientras "Remix" comienza con: "La cajera del minimarket del pueblo me dijo: escribo poemitas en internet" (2014: 15), "Patria automática", arranca así: "Me dijo: esto no es ciencia ficción. Me dijo: esto no es nada. Me dijo: un tío de mi abuelo inventó los robots" (2014: 41). Del mismo modo, en "La dieta del orco" puede leerse: "La mina me dejó, se fue, hueón; no cachó que yo estaba hecho de alta fantasía" (2014: 53); y en "Death Metal", el cuento que cierra el volumen, sabemos que "Las bandas del pueblo escribían sus canciones satánicas con un diccionario de inglés-español en la mano [...]. Imagínatelas cantadas en un inglés chapurreado, sonando pésimo por los parlantes" (2014: 147-148). ¿A quién le dicen estas cosas?, ¿quién es el "hueón" al que se refiere el escritor amante de Tolkien?, ¿quién debe imaginarse esas letras de canciones metaleras? Evidentemente, hay alguien ahí. Intuimos, primero, que el narratario en los cuentos de Bisama parece más estable que el narrador, quien, como analizamos, habla, se gira, confunde, reitera, omite. El narratario parece abierto y dispuesto a oír precisamente las cosas más escabrosas y espeluznantes de aquello que le irán contando. Y segundo, tomando en específico el caso de "Patria automática" (la historia alucinante de que los robots los inventó un chileno durante el siglo XIX), pero que puede extrapolarse al resto de los cuentos en mayor o menor medida: quien refiere la historia (el tío-bisnieto) ha conocido los hechos de boca de su abuelo, que a su vez los ha conocido de su tío, dejándonos, en conclusión, la evidencia de que los hechos no son hechos, sino palabras que edifican elusivamente una narración. La experiencia perceptiva directa con el suceso está vedada. Por lo tanto, debido a este juego de narratarios que se vuelven narradores, lo que se sacrifica para el cuento tradicional es que, y usando los términos de Genette ${ }^{18}$ casi no hay mímesis, solo diégesis de una diégesis (como en "Ciento sesenta y dos mil ochocientos segundos" o "Ho Chi Minh City") o, incluso, diégesis de la diégesis de una diégesis (como en "Patria automática"). ${ }^{19}$

\footnotetext{
${ }^{18}$ Vid. "Fronteras del relato": "La representación literaria, la mímesis de los antiguos, no es pues el relato más los «discursos»: es el relato y sólo el relato [...]; la imitación perfecta ya no es una imitación, es la cosa misma y finalmente la única imitación es la imperfecta. Mímesis es diégesis" (Genette, 2006: 203, cursivas en el original).

${ }^{19}$ Son pocos los críticos que advirtieron en su momento este procedimiento. La primera en notarlo fue Alida MayneNicholls Verdi, quien en un breve análisis periodístico a Los muertos menciona: "Una de las particularidades de los cuentos es la intermediación de los relatos. «Patria automática» comienza con un: «Me dijo» que da cuenta de que el yo de estos relatos está extraviado, es un falso yo, o este ha sido arrebatado: los personajes no son dueños de sus propias historias. Escuchamos (leemos) el yo de la insomne que espera morir; pero en realidad es otro sujeto recontando su historia. Y en «Patria...» la historia que relata el periodista que hace una nota sobre inventos, es un relato que hace un notario anciano, quien reproduce lo que le contó su abuelo; la historia, sin embargo, no es sobre ninguno de ellos" (2014: párr. 4). También, Ricardo Martínez, uno de los que prontamente escriben sobre el volumen, repara en este aspecto: "[M] parece que la mayoría de los cuentos que componen esta entrega de Bisama circula en torno al mismo principio: contemos la vida de personas que dejan de lado su propia vida por aferrarse a la identidad que regala la literatura, o la música, o los artefactos culturales. Personas que constituyen su existir sobre la base de algo ajeno, personas que dejan de vivir sus vidas para vivir otras vidas, muertos" (2014: párr. 9).
} 
Aún más enfático: el narratario es capaz, incluso, de poner un cuestionamiento que este tipo de historias puedan realmente contarse bajo las estructuras tradicionales. Por ejemplo, el ominoso cuento "Ciento sesenta y dos mil ochocientos segundos" arranca de esta forma:

¿Ves esa mina de allá?

Se está muriendo, huevón.

Se muere hoy o mañana y está sentada en la barra esperando la muerte [...]. Yo ayer hablé con ella. Me acerqué a la barra y nos tomamos un trago. Ella invitó. Ella paga. Siempre. Me contó lo que le pasaba. (2014: 31$)$

En este diálogo, ${ }^{20}$ donde se revela que una chica ha sido diagnosticada con una enfermedad terminal $-\mathrm{y}$ que, como vimos en la sección anterior, el narrador es displicente con la misma: "Me dijo el nombre de la enfermedad, pero no lo retuve. No importa" (2014: 32) —, quien emite la historia está en una posición de escepticismo para con el narratario y también para con el lector. Este emisor es el único que conoce los materiales, jirones de una narración que, para volver a una imagen anterior, parece un tapiz lleno de huecos: una muchacha se muere acodada en la barra de un tugurio, "pero me voy tranquila, me dijo. Me voy tranquila porque encontré a mi padre, me dijo la chica que se está muriendo de insomnio, la mina que no puede bajar los párpados" (2014: 31). Al igual que otros textos de Bisama, como "La dieta del orco", la historia del músico de glam rock en Caja negra y las novelas Música marciana y El brujo, en este cuento aparece una temática recurrente: la búsqueda del padre ausente y la ilusión de que, al encontrarlo, será posible cerrar episodios dolorosos. La muchacha que va a morirse, según el narrador, inicia la pesquisa de su padre por distintos rincones de Valparaíso, notando cómo entre el insomnio, el alcohol y los medicamentos su percepción se altera, asunto clave para esta desestimación del sujeto que cuenta primero como narratario cabal y luego como narrador fiable:

Me preguntó cómo me sentía. Le dije que como la mierda. Que morirse así no se lo deseaba a nadie. Que mi capacidad de atención estaba destruida. Que me había convertido en una ciudad abandonada. Que las pastillas evitaban que me cayera al suelo, muerta. El insomnio tiene eso. Quedas atrapado en un lugar que no existe. A solas, le dije. Las palabras se transforman en dagas, en clavos. Las oraciones, en cámaras de tortura que funcionan como máquinas al interior del paladar. Tu cuerpo deja de ser tu cuerpo. Se vuelve algo ajeno. Captas cada sonido, cada hueso girando, cada músculo doblándose [...]. Dejas de comprender lo que te rodea. El interior y el exterior se disuelven, se hacen líquidos. A pesar de estar despierta, vives la pesadilla. Tú eres la pesadilla. Cambias los colores. El aire se respira más espeso, más turbio. Así me sentía. (2014: $37)$.

La muchacha le refiere al narrador que encontró finalmente a su padre promocionando productos en un supermercado disfrazado de pollo. La visión grotesca e hilarante de la figura paterna, cuando la expectativa parecía proporcionarnos otra más digna y épica, nos matiza y desestabiliza el juego de narratarios/narradores. ¿Es posible confiar en lo que el narrador dice que la muchacha ve, debido a su percepción alterada por pastillas e insomnio?, ¿puede esta historia,

\footnotetext{
${ }^{20}$ Siguiendo a Mayne-Nicholls: "Los relatos se convierten en escritura por la fuerza que imprimen, pero, al mismo tiempo, se resisten a la palabra escrita, o a la fijación que esta supone; por el contrario, apelan a la oralidad, a que una tenga la impresión de que está escuchando y no leyendo; que una es otra más en esa cadena del «me dijo que», sin parafrasear, sino asumiendo la voz" (2014: párr. 6).
} 
que está pasando de mano en mano, tener un grado supremo de fiabilidad? En suma, ¿quién está alucinando, la muchacha o el narrador?, ¿dónde es posible notar alguna realidad fenoménica confiable en esto, que es pura diégesis delirante?

La muchacha le refiere al narrador en el bar, al final del relato, algo excepcional para las trasgresiones aquí vistas: "Después me fui [...]. Me metí a un cine donde pasaban una cinta de acción pero no entendí nada. Las escenas eran inconexas, los personajes cambiaban de rostro, el final parecía el principio y el principio era el final; los muertos volvían a la vida" (2014: 37-38). Esta cita tiene una vocación autorreflexiva evidente y trae a colación lo planteado más arriba en torno a las estructuras inéditas de narrar que, decíamos, Bisama parece aprender de Bolaño. Aquí no hay progresión ni desenlace alguno; lo que hay es un bucle, un loop donde, parece, la narración queda atrapada. La última sentencia de la chica, donde se entrelazan protagonista, narrador y narratario, es: "La combinación de vodka con pastillas es agradable, amable. Simpática. Estira el tiempo, me dijo ella, huevón. Hace todo más lento, dijo. Como una canción que nunca termina. Como esa canción que se repite una y otra vez en todos los supermercados de la ciudad, dijo ella" (2014: 38). Nunca sabremos si, realmente, la chica muere o se trata de un afiebrado relato del narrador, pues el cuento, más que concluir, se interrumpe.

Podemos afirmar entonces que el narrador bisamiano fracasa en su empresa de darle cierre a los cuentos; pero sus narratarios, como receptáculos de las historias más extremas, tampoco cumplen estrictamente su cometido: sí "pone[n] de relieve ciertos temas", pero no "hace[n] progresar la intriga" y menos se "convierten en portavoces morales de la obra", si volvemos a revisar las líneas teóricas de Prince. Estas historias, entonces, quedan girando en espirales constantes o bien, por intervención de estas figuras textuales, quedan suspendidas en estructuras que no son progresivas ni triádicas.

Narradores falibles, narratarios inestables, estructuras en bucle o cuenta regresiva, relatos que empiezan o acaban fuera de las fronteras del relato. Finalmente, luego de identificar que los relatos incluidos en Los muertos de Álvaro Bisama en realidad se aprovechan de diversos procedimientos o modulaciones experimentales, cabría preguntarse dos cosas (y cualquiera de esas dos cosas daría para un estudio profundo de más aristas en la obra de este autor chileno): ¿funciona Los muertos como, y trayendo a colación el concepto de José Sánchez Carbó, una "colección de relatos integrados"? Al final de "Noize", y siguiendo la idea de que en las entrañas de los propios cuentos hay claves metaliterarias o autorreflexivas que iluminan su lectura, se señala: "Me habló de cómo en el fondo lo que importaba eran las junturas, los bordes, los puntos de enlace, dijo" (2014: 144). De esta forma, si nos concentramos en las junturas y puntos de enlace, advertiremos que la chica que se muere y busca a su progenitor en "Ciento setenta y dos mil ochocientos segundos", menciona en un momento de su pesquisa, al hablar con una de las mujeres de su padre: "Ella me contó que la había dejado por una cajera de supermercado" (2014: 34). Pronto sabremos que la cajera se llama Estela. Ahora, ¿funciona esta mención como punto de enlace para conectar este tercer cuento con el primero, "Remix", si ahí puede leerse de manera patente: "La cajera del minimarket del pueblo me dijo [...]" (2014: 15, la cursiva es nuestra)? ¿Es Estela el personaje que se mutila oyendo bandas de death metal en "Remix"?, ¿y cuáles bandas, las que se arman y desarman en el cuento de ese nombre, "Death Metal", que cierra el 
volumen? Asimismo, al final del relato de la moribunda, el narrador menciona: "Era lo único que tenía. La arena negra de los segundos" (2014: 38, la cursiva es nuestra), conectando posiblemente sus peripecias con el séptimo cuento, el del ladrón de coches que se enamora de una muchacha "fantasma". ¿Es este chico, el ladrón de automóviles, el narrador o, posiblemente, el narratario de "Ciento setenta y dos mil ochocientos segundos"? Cabría aplicar, pues, la metodología de Sánchez Carbó a estudios posteriores de Los muertos, si además de estas menciones, encontramos paralelismos entre el protagonista de "Ho Chi Minh City", quien cree ver un mapa de señales secretas con las distintas muertes que se suscitan en Saigón, y el de "Pozo", quien sentencia: "La ciudad me había enviado ahí. Las líneas del stencil eran un mapa secreto para llegar a aquel lugar" (2014: 115), etcétera.

Por otra parte, en este libro de 2014 hay evidentes reiteraciones o, como el nombre del primer cuento lo indicaba, remix de temas que ya se han vuelto obsesivos y característicos de la narrativa de Bisama, y que, para un ensayo de mayor envergadura, son plausibles de estudiarse desde, por ejemplo, la teoría tematológica: detrás de toda aquella fachada de extravagancia, terror, música pesada, tribus urbanas y alta fantasía, hay dolor por la ausencia de algún familiar ("La dieta del orco", "Arena negra"); también, deseo de conectarse con los padres, por muy extraños o infames que hayan sido ("Muchacha nazi", "Ciento sesenta y dos mil ochocientos segundos", "Noize") y una voluntad casi desesperada no solo por comprender, sino por redimirse a través de la creación artística (fotografiar, en "Ho Chi Minh City", pintar en "Pozo", escribir en "La dieta del orco").

No podríamos clasificar de forma tan categórica a Bisama como "anticuentista"; sin embargo dentro de la cuentística chilena contemporánea es uno de los escritores que mayores riesgos ha tomado para llevar al género a decir más cosas en, precisamente, sus entrelíneas y omisiones.

\section{Bibliografía}

ANDERSON IMBERT, Enrique (2007): Teoría y técnica del cuento. Barcelona: Ariel, $2^{\mathrm{a}}$ edición. [1979]

ARISTÓTELES (1999): Poética (edición trilingüe de Valentín García Yebra). Madrid: Gredos, $3^{\text {a }}$ reimpresión.

ASENSI PÉREZ, Manuel (2006): “Auto-reflexividad y «literatura»". Los años salvajes de la teoría: Ph. Sollers, Tel Quel y la génesis del pensamiento post-estructural francés. Valencia: Tirant Lo Blanch, 267-344.

BAL, Mieke (2009): Teoría de la narrativa. Una intrioducción a la narratología. Madrid: Cátedra, $8^{\mathrm{a}}$ edición.

BARTHES, Roland (1987): "Sobre la lectura”. El susurro del lenguaje. Más allá de la palabra y la escritura. Barcelona: Paidós, 39-50.

--- (2006): "Introducción al estudio estructural del relato". En Roland Barthes, et. al.: Análisis estructural del relato. México: Coyoacán, 9-44. 
BAJTÍN, Mijaíl M. (1989): Teoría y estética de la novela. Madrid: Taurus.

BISAMA, Álvaro (2014): Los muertos. Santiago de Chile: Ediciones B.

BOTTINELLI, Alejandra: "Narrar (en) la «pos»: La escritura de Álvaro Bisama, Alejandra Costamagna, Alejandro Zambra". Revista Chilena De Literatura 92 (abril 2016): 7-31. DOI: http://dx.doi.org/10.4067/S0718-22952016000100001

BRESCIA, Pablo: “Asedios a la forma: teorías (clásicas y nuevas) del cuento”. Revista Perifrasis V/9 (2014): 65-78. DOI: https://doi.org/10.25025/perifrasis20145905

CORTÁZAR, Julio (1994): “Algunos aspectos del cuento". Obra Crítica 2. Buenos Aires: Alfaguara, 365-385.

FOUCAULT, Michel (1996): “Lenguaje y literatura”. De lenguaje y literatura. Barcelona: UAB, 63-106.

GENETTE, Gérard (2006): "Fronteras del relato". En Roland Barthes, et. al.: Análisis estructural del relato. México: Coyoacán, 199-213.

JAKOBSON, Roman (1980): "Dos aspectos del lenguaje y dos tipos de trastornos afásicos". Fundamentos del lenguaje. Madrid: Editorial Ayuso, 99-143.

JOYCE, James (1994): “Los muertos”. Dublineses. Barcelona: Altaya, 291-347.

MARTÍNEZ, Roberto: “Los muertos, de Álvaro Bisama”. La Tercera Cultura, 9 de febrero de 2014. Recuperado el 5 de abril de 2019, de https://terceracultura.cl/2014/02/los-muertosde-alvaro-bisama/

MAYNE-NICHOLLS VERDI, Alida: "Columna de libros: «Los muertos» de Álvaro Bisama". Publimetro Chile online, 10 de febrero de 2014. Recuperado: 5 de abril de 2019, de https://www.publimetro.cl/cl/columnas/2014/02/10/columna-libros-muertos-alvarobisama.html

PALAZUELOS, Juan Carlos (2003): El cuento hispanoamericano como género literario. Santiago de Chile: RIL Editores.

PIGLIA, Ricardo (2000): "Tesis sobre el cuento". Formas breves. Barcelona, Anagrama, 103112. DOI : https://doi.org/10.3406/ameri.1987.907

PRINCE, Gerald (2001): “El narratario”. En Enric Sullà (ed.): Teoría de la novela. Antología de textos del siglo XX. Barcelona: Crítica, $2^{\mathrm{a}}$ edición, 151-162.

RÍOS BAEZA, Felipe A.: "Metaliteratura e ideología: Apuntes para una teoría". Isla Flotante. Revista de Comunicación y Literatura de la Escuela de Periodismo de la Academia 6 (2017): 77-86. DOI: https://doi.org/10.25074/07199295.6.652

SÁNCHEZ CARBÓ, José (2012): La unidad y la diversidad. Teoría e historia de las colecciones de relatos integrados. Puebla: Universidad Iberoamericana.

SCHOLZ, László (2001). Los avatares de la flecha. Cuestionamiento del principio de linealidad en el cuento moderno hispanoamericano. Salamanca: Universidad de Salamanca.

STEVICK, Philip (1971): Anti-Story: An Anthology of Experimental Fiction. New York: The Free Press. 
SOLLERS, Phillipe: "Des grandes irrégularités de langage". Critique 195-196 (agostoseptiembre 1963): 795-802.

UNIVERSIDAD DIEGO PORTALES (2013): "Exposición: libros quemados, escondidos y recuperados a 40 años del golpe". Biblioteca Nicanor Parra (sitio web), Universidad Diego Portales. Recuperado el 5 de abril de 2019, de http://www.bibliotecanicanorparra.cl/exposicion-libros-quemados-escondidos-yrecuperados-a-40-anos-del-golpe/

(C) Felipe Adrián Ríos Baeza

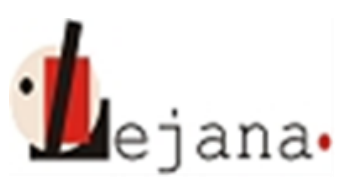

http://ojs.elte.hu/index.php/lejana

Universidad Eötvös Loránd, Departamento de Español, 1088 Budapest, Múzeum krt. 4/C 